\title{
Isolation of Keratinophilic Fungi and Aerobic Actinomycetes From Park Soils in Gorgan, North of Iran
}

\author{
Esmat Malek ${ }^{1}$, Mahnaz Moosazadeh ${ }^{1}$, Parastoo Hanaf ${ }^{1}$, Ziba Abbasi Nejat ${ }^{1}$, Abolfazl Amini ${ }^{1}$, \\ Rasool Mohammadi ${ }^{2}$, Faramarz Kohsar ${ }^{1}$, Farhad Niknejad ${ }^{3, *}$ \\ ${ }_{1}^{1}$ Department of Laboratory Sciences, School of Paramedicine, Golestan University of Medical Sciences, Gorgan, IR Iran \\ ${ }_{3}^{2}$ Department of Biostatistics, School of Medicine, Golestan University of Medical Sciences, Gorgan, IR Iran \\ 3 Laboratory Science Research Center, Golestan University of Medical Sciences, Gorgan, IR Iran \\ ${ }^{*}$ Corresponding author: Farhad Niknejad, Laboratory Science Research Center, Golestan University of Medical Sciences, Gorgan, IR Iran. Tel:+98-1714436102-8, Fax: +98-1714423630, \\ E-mail: niknejad@goums.ac.ir.
}

Received: April 1, 2013; Revised: July 8, 2013; Accepted: August 7, 2013

\begin{abstract}
Background:Keratinophilic fungiare a group of fungi that colonize in various keratinous substrates and degrade them to the components with low molecular weight. This study was conducted to determine the prevalence of keratinophilic fungi and aerobic Actinomycetes in soil of city parks in Gorgan.

Objectives: In this study, we surveyed the city park soils of Gorgan (a northern province of Iran) to determine the identities and diversity of soil aerobic Actinomycetes, keratinophilic and non-keratinophilic fungi.

Materials and Methods: A total of 244 soil samples were collected from 22 different parks of Gorgan, North of Iran. The samples were collected from the superficial layer with depth not exceeding than 0-10 cm in sterile polyethylene bags. We used hair bait technique for isolation keratinophilic fungi. The colonies identified by macroscopic and microscopic characterization after slide culturing. Actinomycetes were isolated by antibiotic dilution methods and detected by using physiological tests such as Lysozyme, Casein, Xanthine, Hypoxanthine, Gelatin, Urea Broth, and modified acid-fast stain.

Results: Totally, 75 isolates of aerobic Actinomycetes were detected that Actinomadura madurae and Nocardia asteroides were the most prevalent strains, with 14.66 and $28 \%$ prevalence respectively. Microsporum gypseum was more frequent than other keratinophilic fungi (22.96\%) and Aspergillus spp. was the most species of saprophyte fungi (15.92\%).

Conclusions: This study showed that the collected soil from studied areas was rich of keratinophilic fungi and Actinomycetes, therefore hygiene protocol should be taken to prevent the spread of pathogenic and saprophytes fungi in the environment of susceptible person.
\end{abstract}

Keywords: Keratinophilic fungi; Actinomycetes; City Park Soils; Iran

\section{Background}

Keratinophilic fungi are a group of fungi that colonize in various keratinous substrates and degrade them to the components with low molecular weight (1). Soil is rich in keratinous components which are most conducive for the growth and occurrence of keratinophilic fungi (2). Dermatophytes, one of the most keratinophilic fungal have been divided into three categories according to their natural habitats. Anthropophilic, human being are the natural hosts: Zoophilic, a variety of animals are natural hosts; Geophilic, the soil is the natural habitat (2). Geophilic dermatophytes are a group of keratinophilic fungi which cause superficial infections in keratinized tissues of human and animals.

Superficial mycoses reported throughout the world, and the infections are very contagious. The soil is also regarded as the reservoir of most keratinophilic microorganisms including non-dermatophytes fungi such as saprophytic fungi (3). Rich keratinous materials in soil are the most reason of high incidence of keratinophilic fungi (4).

The aerobic Actinomycetes are a various group of Gram positive, branching, filamentous, obligate aerobic and relatively slow-growing bacteria that belong to the order Actinomycetales. The major groups of the order Actinomycetales are Actinoplanetes, Maduromycetes, Nocardia, Actinomycetes, and Streptomycetes (5). These bacteria are considered as spore-forming bacteria which causing health problems. It is well known that aerobic Actinomycetes are abundantly found in soil and cause opportunistic infections in human and animals and even in some cases cause death (6). Mycetoma and nocardiosis are sporadically spread in Iran and etiological agents are vary from

Implication for health policy/practice/research/medical education:

The results of the study contributed to a better understanding of the incidence and the pattern of soil-borne fungi which may be useful for further epidemiological investigation and awareness of people who are in contact with soils.

Copyright (C) 2013, Ahvaz Jundishapur University of Medical Sciences; Published by Kowsar Corp. This is an open-access article distributed under the terms of the Creative Commons Attribution License, which permits unrestricted use, distribution, and reproduction in any medium, provided the original work is properly cited. 
country to country.

Increased rate of infections by aerobic Actinomycetes, specially Nocardia genus and diverse and the broad range of clinical illnesses specially the systemic and disseminated forms of nocardiosis in patients with cancer, tuberculosis, diabetes, AIDS and patients under treatment with immunosuppressive drugs in the world disclose the importance of detection of these microorganisms (7).

\section{Objectives}

The keratinophilic fungi and aerobic Actinomycetes are distributed worldwide (8-11) which is more attracted Iranian researches in recent years $(4,12-15)$. In this study, we surveyed city park soils of Gorgan (a northern province of Iran) for determine the identities and diversity of soil aerobic Actinomycetes, keratinophilic and non-keratinophilic fungi.

\section{Materials and Methods}

A total of 244 soil samples were collected from 22 different parks of Gorgan, Northern of Iran over the period of the study (September to December 2012). The soil samples were collected from the superficial layer with depth not exceeding than $10 \mathrm{~cm}$ and kept in sterile polyethylene bags. The samples were transferred to the laboratory for processing. We used hair bait technique for keratinophilic fungi isolation (16). To this purpose fifty grams of each sample was taken in a separate sterilized Petri dish. Sterilized distilled water was added to provide moisture to the soil. Sterilized human hair was used as baits. The hair was homogeneously scattered only on wet soil. Each Petri dish was incubated at $28+2^{\circ} \mathrm{C}$ for $3-4$ weeks in culture room and were moistened with sterile distilled water whenever necessary. The plates were observed periodically for the isolation and identification of keratinophilic fungi (16).

Isolation were carried out by direct transfer of mycelium from the baits to Sabouraud dextrose agar (Merck, Germany) medium containing cyclohexamide (Sigma Aldrich, USA) (1 mg/mL) and chloramphenicol (Sigma Aldrich, USA $(0.1 \mathrm{mg} / \mathrm{mL})$ and then incubated at room temperature for a period of two weeks (14). Identification of fungal culture was done base on the colony characters, pigmentation, different media study and morphological characterization after slide culturing (17). For aerobic Actinomycetes isolation, five grams of each soil sample was added to a test tube containing $10 \mathrm{~mL}$ of sterile physi- ological saline $(0.9 \% \mathrm{NaCl})$ and mixed for 3 minutes. The suspension was incubated for 15 minutes and thereafter, $3 \mathrm{~mL}$ of the supernatant solution was transferred to another sterile tube and $1.5 \mathrm{~mL}$ of antibiotic solutions of streptomycin and chloramphenicol $(0.2 \mathrm{mg} / \mathrm{mL})$ was added and incubated for half an hour after being stirred up.

The solution was shaking again and one $\operatorname{drop}(0.05 \mathrm{~mL})$ was added to a Sabouraud dextrose agar (Merck, Germany) medium, containing $0.5 \mathrm{mg} / \mathrm{mL}$ of cycloheximide (Sigma Aldrich, USA) and another drop to Brain-Heart infusion agar (Merck, Germany) containing cycloheximide (Sigma Aldrich, USA) (0.5 mg/mL) and kanamycin (Sigma Aldrich, USA) $(0.025 \mathrm{mg} / \mathrm{mL})$ immediately, and incubated at $35^{\circ} \mathrm{C}$ for $2-3$ weeks. The colonies were selected and streaked on new plates of aforementioned culture media. Actinomycetes on the plates were identified as colored, dried, rough, with irregular/regular margin, generally convex colony. The plates were kept in a $35^{\circ} \mathrm{C}$ incubator and the possible growth was examined for up to 2 or 3 weeks.

The streak plate method was used to purify the Actinomycetes. Actinomycetes were recognized by using physiological tests such as Lysozyme, Casein, Xanthine, Hypoxanthine, Gelatin, Urea Broth (HiMedia, India) and staining with the carbol-fuchsin modified acid-fast stain with a weak (0.5-1\%) sulfuric acid decolorizing solution (12). The $\mathrm{pH}$ of the samples was measured immediately in a 1:5 soil/deionised water suspension (w/v) using a $\mathrm{pH}$ meter according to A1-Musallam (18).The $\mathrm{pH}$ of distilled water was also detected before adding to the soil sample.

\section{Results}

Among 244 soil samples, 195 (79.91\%) samples were positive for keratinophilic fungi and aerobic Actinomycetes (Table 1 and Table 2). Keratinophilic fungi belong to 17 species and 75 aerobic Actinomycetes species representing 2 genera in this research. The most common isolates were Microsporum gypseum 62 (22.96\%), Actinomadura madurae 11 (14.66\%), Nocardia asteroides 21 (28\%). Non-dermatophytic keratinophilic fungi including Aspergillus spp. 43 (15.92\%) and Chrysosporium spp. 38 (14.07\%) were more than the other saprophytic fungi.

In the present study the Chrysosporium spp. and M. gypseum were mostly detected in the soil samples with $\mathrm{pH}$ : 6.0-6.5 (71\%) and pH: 5.7-6.7 (82.3\%) but Actinomycesc spp. and Nocardia spp. isolated with the broad range of $\mathrm{pH}$ from 4.7-7.5 and 5.3-7.2 respectively. 
MalekE et al.

\begin{tabular}{ll}
\hline Table 1. Frequency of Fungi Isolated from Soils of 22 Different Parks in Gorgan, Northern of Iran \\
\hline Isolated Fungal Species & No. $(\%)$ \\
\hline Microsporum gypseum & $62(22.96)$ \\
\hline Aspergillus spp. & $43(15.92)$ \\
\hline Chrysosporium spp. & $38(14.07)$ \\
\hline Penicillium spp. & $29(10.74)$ \\
\hline Gliocladium spp. & $25(9.25)$ \\
\hline Mucor spp. & $24(8.88)$ \\
\hline Acremonium spp. & $21(7.77)$ \\
\hline Rhizopus spp. & $6(2.22)$ \\
\hline Syncephalestrum spp. & $5(1.85)$ \\
Paecilomyces spp. & $4(1.48)$ \\
Alternaria spp. & $4(1.48)$ \\
Fusarium spp. & $4(1.48)$ \\
\hline Cladosporium spp. & $1(0.37)$ \\
\hline Verticillium spp. & $1(0.37)$ \\
\hline Monilia spp. & $1(0.37)$ \\
\hline Sepedonium spp. & $1(0.37)$ \\
\hline Syncephalestrum spp. & $1(0.37)$ \\
Total & $270(100)$ \\
\hline & \\
\hline
\end{tabular}

Table 2. Frequency and pH of Aerobic Actinomycetes Isolated from Soils of 22 Different Parks in Gorgan, Northern of Iran

\begin{tabular}{lll}
\hline Isolated Aerobic Actinomycetes & No. $(\%)$ & pH Range \\
\hline Actinomadura madurae & $11(14.66)$ & $4.7-7.5$ \\
\hline Actinomyces bovis & $4(5.33)$ & $5.9-7.4$ \\
\hline Actinomyces eriksoni & $1(1.33)$ & 5.8 \\
\hline Actinomyces spp. & $7(9.33)$ & $5.5-7.5$ \\
\hline Nocardia asteroides & $21(28)$ & $5.9-7.1$ \\
\hline Nocardia brasiliensis & $17(22.66)$ & $5.6-7.1$ \\
\hline Nocardia otitidiscaviarum & $3(4)$ & $5.5-6.2$ \\
\hline Nocardia asteroides spp. & $11(11.66)$ & $5.3-7.2$ \\
\hline
\end{tabular}

\section{Discussion}

The survey on dermatophytes and other keratinophilic fungi in the soil of parks and gardens in large towns is very interesting because of the relationship between the number of people living in the area and the presence of such fungi in the soil (19). Keratinophilic fungi play an important role in the natural degradation of keratinized residues of the soil $(20,21)$. Soils are rich in organic materials and provide favorable conditions for spread of fungi. The prevalence of keratinophilic fungi and aerobic Actinomycetes in soils of Gorgan, Northern of Iran has not been studied previously. Several investigations have been done in various part of Iran during the recent years and showed that a rich variety of keratinophilic fungal flora exists in the soils of studied area $(13,14,22,23)$.

Keratinophilic fungi mostly preferred slightly acidic to alkaline soil (24) and in the present investigation, the soil $\mathrm{pH}$ range varied from 4.5 to 8.0. Most of the fungi were isolated from neutral to slightly acidic soils. No keratinophilic fungi growth was reported below in soil with $\mathrm{pH}$ 5.0 and above 8.0. According to a research conducted by Jain and Sharma, most of the keratinophilic fungi were isolated from pH 6.5 to 8.5 (25). Meinhof et al. (26) and Kaben et al. (27) suggested that highly acidic soils were mostly a poor source of keratinophilic fungi.

Fillipello Marchisio (28) isolated 57 keratinophilic fungi from public parks in Italy and found that Microsporum, Aphanoascus, Chrysosporium, Malbranchea, and Geomyces species were the most active keratinolytic fungi. Gugnani et al. (29) found that M. gypseum complex, a well-known geophilic dermatophyte, was the most frequently recovered species in soils of St. Kitts and Nevis (the same as our results) and $C$. indicum was the next most common spe- 
cies recovered but in our study Chrysosporium spp. were placed as the third. The variation and prevalence of these microorganisms in soil depend on the environmental and nutritional conditions of areas and it may be varied if the study were carried out all year long.

Opportunistic infections caused by aerobic Actinomycetes are well known and are found in soil and cause death in human and animals in some occasions. Nocardia spp. are distributed in the environment and well known as saprophytic soil contaminates. The classification of Nocardia appears to be significant beneficial for health policy defining the geographic distribution of these organisms. Members of the genus Nocardia are most commonly associated with a diverse of opportunistic infections in both immunocompromised and immunocompetent hosts (30). Mycetoma and nocardiosis are sporadically spread in Iran and different etiological agents are presented in soil such as $N$. brasiliensis, N. asteroides, A. peletieri, and A. madurae can be inoculated in the skin and may cause actinomycetoma (7). We found that $N$. asteroides 21 (28\%) and A. madurae 21 (14.66\%) were more prevalent than other aerobic Actinomycetes species that is one of the most common agent of actinomycetoma and nocardiosis in Iran.

In our study, $N$. brasiliensis compromised $22.66 \%$ of all Actinomycetes species and it is very important not only for frequently rate of infection in immunocompromised patients, but also it can cause cutaneous and disseminated infections in immunocompetent people. Cutaneous nocardiosis follows cutaneous inoculation by any of the pathogenic Nocardia, with $N$. brasiliensisis responsible for 80 percent of infection cases (31).

In this study, aerobic Actinomycetes in soil were frequently isolated from different parks of Gorgan and it may be concern for designing effective preventive strategies in health regulation in immunocompromised patients and the awareness of people to contact with soils. In addition, the results of the study contributed to a better understanding of the incidence pattern of soil-borne fungi and may be useful for further epidemiological investigation. It is notable that results of this study indicated that soil sources have high prevalence of keratinophilic fungi including geophilic dermatophytes and aerobic Actinomycetes. Although most of those are seldom involved in infections but have the potential to cause infection and it is a remarkable finding for public health significance.

\section{Acknowledgements}

We would like to thank the Vice-chancellor of Research and Technology of Golestan University of Medical Sciences for their financial support of this study and Dr. E. Zibafar for his help us in research.

\section{Financial Disclosure}

The authors received no external funding for this research.

\section{Funding/Support}

The study was financially supported by Deputy of Research, Golestan University of Medical Sciences, with grant No. 35.1741, Gorgan, Iran.

\section{References}

1. Gugnani Harish C. Nondermatophytic filamentous keratinophilic fungi and their role in human infection. Rev Iberoam Micol. 2000;17:109-14.

2. Jain N, Sharma M. Biodiversity of keratinophilic fungal flora in university campus, jaipur, India. Iran J Public Health 2012;41(11):27-33.

3. Gupta AK, Ryder JE, Chow M, Cooper EA. Dermatophytosis: the management of fungal infections. Skinmed. 2005;4(5):305-10.

4. Zarrin M, Haghgoo R. Survey of keratinophilic fungi from soils in Ahvaz, Iran. Jundishapur J Microbiol. 2011; 4(3):191-4.

5. McNeil MM, Brown JM. The medically important aerobic actinomycetes: epidemiology and microbiology. Clin Microbiol Rev. 1994;7(3):357-417.

6. Anonymous . [Indoor air guideline. Department of Social Affairs and Health]. Helsinki, Finland: Edita. 1997.

7. Saubolle MA, Sussland D. Nocardiosis: Review of Clinical and Laboratory Experience. J Clin Microbiol. 2003;41(10):4497-4501.

8. Abdullah SK, Hassan Dina A. Isolation of dermatophytes and other keratinophilic fungi from surface sediments of the Shatt Al-Arab River and its creeks at Basrah, Iraq. Mycoses. 1995;38(34):163-166

9. Deshmukh SK, Mandeel QA, Verekar SA. Keratinophilic fungi from selected soils of Bahrain. Mycopathologia. 2007;165(3):143147.

10. Deshmukh Sunil K, Verekar Shilpa A. Incidence of keratinophilic fungi from the soils of Vedanthangal Water Bird Sanctuary (India). Mycoses. 2011;54(6):487-490.

11. Vidyasagar GM, Hosmani Narayan, Shivkumar D. Keratinophilic fungi isolated from hospital dust and soils of public places at Gulbarga, India. Mycopathologia. 2005;159(1):13-21.

12. Aghamirian MR, Ghiasian SA. Isolation and characterization of medically important aerobic actinomycetes in soil of iran (2006 - 2007). Open Microbiol J. 2009;3:53-7.

13. Hedayati MT, Mohseni-Bandpi A, Moradi S. A survey on the pathogenic fungi in soil samples of potted plants from Sari hospitals, Iran.J Hos Infect. 2004;58(1):59-62.

14. Kachuei R, Emami M, Naeimi B, Diba K. Isolation of keratinophilic fungi from soil in Isfahan province, Iran. J Mycol Med. 2012;22(1):8-13.

15. Moallaei $\mathrm{H}$, Zaini $\mathrm{F}$, Pihet $\mathrm{M}$, Mahmoudi M, Hashemi J. Isolation of keratinophilic fungi from soil samples of forests and farm yards. Iran JPub Health. 2006;35(4).

16. Vanbreuseghem $\mathrm{R}$ editor. . [Biological technique for isolating dermatophytes from soil]. Annales de la Société belge de médecine tropicale.;1952. p. 173.

17. de Hoog Gerrit Sijbrand, Guarro J, Figueras MJ, Gené J. Atlas of clinical fungi.: Centraalbureau voor Schimmelcultures Utrecht; 2000.

18. Al-Musallam AA. Distribution of keratinophilic fungi in animal folds in Kuwait. Mycopathologia.1990;112(2):65-70.

19. Mercantini R, Marsella R, Caprilli F, Dovgiallo G. Isolation of dermatophytes and correlated species from the soil of public gardens and parks in Rome. Sabouraudia. 1980;18(2):123-8.

20. Marchisio Valeria Filipello. Keratinophilic fungi: their role in nature and degradation of keratinic substrates. Biology of dermatophytes and other keratinophilic fungi. 2000:86-92.

21. Sharma Rahul, Rajak RC. Keratinophilic fungi: Nature's keratin degrading machines! Resonance. 2003;8(9):28-40.

22. Shadzi S, Chadeganipour M, Alimoradi M. Isolation of keratinophilic fungi from elementary schools and public parks in Isfahan, Iran. Mycoses. 2002;45(11-12):496-9.

23. Zarei Mahmoudabadi Ali, Zarrin Majid. Isolation of dermatophytes and related keratinophilic fungi from the two public parks in Ahvaz.Jundishapur J Microbiol. 2011;1(1):20-23. 
24. Sharma M, Williamson D. Keratinophilic fungal flora of Jaipur District I. Biol Bull India Bhagalpur. 1984;6:195-204.

25. Jain N, Sharma M. Distribution of dermatophytes and other related fungi in Jaipur city, with particular reference to soil $\mathrm{pH}$. Mycoses. 2011;54(1):52-8.

26. Meinhof W, Thianprasit M, Rieth H. [Demonstration, isolation and identification of keratin-utilizing soil fungi pathogenic for the skin]. Arch Klin Exp Dermatol.1960;212:30-48.

27. Kaben U. [the Isolation of Keratinomyces Ajelloi, Trichophyton Terrestre, Microsporum Gypseum and Microsporum Cookei from Soil]. Bull Pharm Res Inst. 1963;45:11-20.

28. Filipello Marchisio V. Keratinolytic and keratinophilic fungi of children's sandpits in the city of Turin. Mycopathologia. 1986;94(3):163-172.

29. Gugnani Harish Chander, Sharma Soni, Gupta Brijinder, Gaddam Srinivas. Prevalence of keratinophilic fungi in soils of St. Kitts and Nevis. J Infect Develop Countries. 2012;6(4).

30. Conville PS, Witebsky FG, Murray PR, Baron EJ, Jorgensen JH, Landry ML, et al. Nocardia, Rhodococcus, Gordonia, Actinomadura, Streptomyces, and other aerobic actinomycetes. Manual of clinical microbiology: Volume 1. 2006(Ed. 9):515-542.

31. Antunes J, Pacheco D, Travassos R, Sequeira H, Filipe P, Marques MS. Actinomycetoma of the chest wall attributed to Nocardia nova after reconstructive surgery. Dermatol Online J. 2012;18(1):4. 